\title{
0 que está acontecendo aqui? \\ Da explicação das ações à atividade de explicar
}

Davide Sparti

Tradução do italiano de Alexandre Braga Massella

Introdução

Quando o cientista social reflete sobre os pressupostos teóricos de sua própria atividade, faz consideraçôes metateóricas sobre o "objeto" teoria. Este artigo é um trabalho de natureza metateórica, em que investigarei uma gama de problemas ligados ao que fazemos quando explicamos as ações. A explicação, que semanticamente remete ao que é distendido e desdobrado, será apresentada no quadro pragmático do explicar como prática teórico-comunicativa. O objetivo é analisar como certos atores sociais operam quando explicam e esclarecer que tipo de atividade é aquela por meio da qual explicamos as ações dos outros. A identificação e a descrição das ações serão inseridas na atividade mais ampla de atribuir motivos e intenções, cuja finalidade é tornar as ações inteligíveis. A consequência dessa perspectiva é deslocar a questão da explicação do plano essencialmente epistemológico para o plano sociológico, ligado aos contextos e às circunstâncias em que se usa a explicação como recurso para agir e interagir.

As teses que pretendo sustentar são as seguintes: explicar é uma atividade de natureza tipicamente comunicativa; ela comporta a (re)descrição de uma determinada ação por parte de um ator social, o "explicador", endereçada a um outro ator social, a audiência, esta entendida como conjunto de "consumidores” da explicação. Daremos atenção à linguagem ordinária; há 
1. Explicar é uma prática humana. Um papagaio que emitisse repetidamente "faz frio" não estaria fornecendo uma explicação para meu resfriado.
2. Sobre a explicação na vida cotidiana, ver Draper (1988, pp. 15-31). sentido em afirmar "explico-lhe alguma coisa", mas não em "compreendo-lhe alguma coisa" (posso, sim, fazer alguém compreender alguma coisa, isto é, posso explicá-la a alguém). Explicar é, em suma, um agir narrativo que pressupõe um interlocutor ${ }^{1}$. Nesse sentido, a explicação não está ligada à figura do participante do curso de ação que é objeto da explicação, mas à figura do participante da atividade de explicar - o explicador, que é assim "destacado" da ação descrita e faz desta um relato.

Distinguirei duas funções da explicação, conforme os diversos modos em que interagem com a audiência. A primeira, que se pode denominar função normativa, está ligada à compreensão interrompida (ou breakdown) e opera restabelecendo a compreensão por meio da criação de uma ordem alternativa àquela interrompida. Essa função tem como condição de satisfação a solução do breakdown. Nesse caso, a explicação opera como um reservatório de instrumentos para restaurar a ordem em xeque, e a sua função é, assim, a de satisfazer um requisito normativo. A segunda, que se pode denominar função de identificação, está ligada de modo perlocutório à compreensão, uma vez que constrói uma teoria ou um vocabulário que oferece, de forma retrospectiva, novas possibilidades de compreensão. A audiência que recebe a explicação a reutiliza para realizar identificações ulteriores de atores e ações. Em ambos os casos, o explicador contribui para uma forma de organização (de produção e de reprodução) da ordem social.

\section{Duas concepções de explicação}

Parece não existir algo como $a$ explicação e bastaria um exame atento da maior parte dos casos judiciários para perceber isso. Há, sim, o explicar, que é uma prática exercida de muitas maneiras. Podemos, por exemplo, explicar a dor de estômago de João dizendo que ela se deve à quantidade de alimento ingerido ou notando que a qualidade do alimento ingerido era ruim e que isso causou sua dor de estômago. As duas formas de explicar mais consolidadas (mas por isso, também, as mais mistificadoras, pois suscitam a ilusão de representar a forma intrínseca de toda explicação) são as chamadas explicação by causes e explicação by reasons, isto é, uma baseada nas causas que produziram o agir e outra, intencionalista, que reconstrói as razões escolhidas pelo ator como finalidade da própria ação (cf. Brandom, 1986, pp. 28-29) $)^{2}$.

A primeira forma deve sua fama à codificação neopositivista. Segundo Hempel e Oppenheim (1948), a essência da explicação está em uma relação 
de implicação causal entre dois enunciados ou grupo de enunciados: o que explica - o explanans - e o que descreve o evento a ser explicado - o explanandum. Por exemplo: por que o carro não dá a partida? (explanandum) Porque esqueceram de desligar o farol e a bateria descarregou (explanans). Com base nessa definição, Hempel e os neopositivistas em geral acabaram por enfatizar um conjunto restrito de explicações, tomando (e subentendendo) uma condição necessária de algumas explicações por uma condição suficiente. A explicação de Clifford Geertz sobre a briga de galos em Bali, a exemplo de muitas explicações relevantes, não invoca leis ou generalizações probabilísticas, mas constrói uma história que nos permite ler o evento da briga de galos como um comentário ou exemplificação da estrutura social balinesa (cf. Geertz, 1973)³. Além disso, se um saber pode se dizer científico quando é capaz de fornecer explicações (e previsões), e explicações de um certo tipo (baseada em leis, diria Hempel), aqui nos interessa a "atividade" de explicar, isto é, o modo pelo qual nos comportamos quando fornecemos explicações, atividade que, por sua vez, não se baseia em leis.

No que diz respeito ao modelo de explicação intencionalista, isto é, by reasons, o ponto relevante não se refere tanto ao seu limite externo, como, por exemplo, o fato de que as razões declaradas pelos atores nem sempre são aceitas como fatores explicativos pela comunidade científica. O importante é que a atribuição e a autoatribuição de razões são elas mesmas um tipo de ação social (fornecer e aceitar razões), comparáveis às ações que as razões presumivelmente produzem. A prática de explicar, em outras palavras, torna atribuíveis e defensáveis razões e motivos cuja validade é decidida, de forma variada, nos contextos em que a prática é exercitada. Charles Wright-Mills foi o primeiro a promover uma concepção segundo a qual os motivos (e as razões) deveriam ser analisados não como "impulsos" (ou alvos) subjetivos da ação, mas como termos de um vocabulário por meio do qual imputamos um significado às ações (nossas e de outros). A produção de motivos e razões é parte do fenômeno a ser investigado e não sua causa ou fundamento da explicação (cf. Wright-Mills, 1940, pp. 904-913).

Tanto o causalismo de inspiração neopositivista como o intencionalismo acabam, assim, por se concentrar quase exclusivamente na explicação como produto (a teoria cinética dos gases para explicar certos fenômenos de condensação, ou a teoria cosmológica de Copérnico para explicar a alternância entre o dia e a noite"), sem considerar suas implicações comunicativas e seu papel social, que é então tomado como externo à lógica explicativa. Trata-se, em suma, de passar da explicação-produto ao contexto em que
3. Sobre a explicação narrativa, ver também Dray (1957). 
4. Não posso decidir o que é uma explicação válida, devo descobri-la no interior da comunidade disciplinar (de maneira similar, posso corrigir alguém, mas não esclarecer o que é a correção em si; o professor não ensina o que é a correção em geral, apenas corrige as aplicaçōes equivocadas da regra). Sobre a pergunta do que torna uma explicaçāo melhor do que outra, ver Fish (1989). Sobre o problema da relaçâao entre adequação explicativa e audiência, e para uma contribuição mais ampla sobre o explicar em relação ao compreender, ver Sparti (1992, cap. 7; 2002).

5. Consideremos um exemplo. Tendemos a pensar a explicação freudiana como um modelo de explicação consolidado e paradigmático, uma explicação produto. Todavia, como mostrou Donald Spence (1982), a explicação psicanalítica produz consequências terapêuticas. Ela é, felizmente, bem-sucedida, porque o analista opera sob o efeito penetrante mas tácito de uma narração contextual (uma narração que entra em ação entre o momento em que o paciente narra e aquele em que o analista compreende e, então, reelabora a narraçăo), e não em virtude de uma suposta correspondência das palavras do analista com o modelo freudiano. Ver também Roth (1989, pp. 467-469). esta se torna resultado paradigmático. Como estamos, em geral, diante de um obstáculo ou enigma resolvido, tendemos a desconsiderar a explicação como processo.

Note bem, a explicação é codificada e comunicada aos outros na forma de teorias ou produtos em relação aos quais faz sentido perguntar: é coerente? É plausível? ${ }^{4}$ Mas a prática crucial do explicar não é, por sua vez, objeto de explicação e permanece implícita na prática explicativa. É este aspecto da explicação, o explicar, que aqui nos interessa ${ }^{5}$.

\section{Breakdowns}

Delineado o âmbito pragmático do explicar, volto agora às circunstâncias em que emerge a solicitação de explicação. Quando - e enquanto - a interação e a comunicação são bem-sucedidas, os membros de uma comunidade supõem compartilhar um fundo de regras e práticas. A fluidez ou agilidade das práticas autoriza a presumir uma compreensão recíproca (a compreensão é aquilo que imaginamos que deva estar presente como componente cognitivo de uma interação bem-sucedida). O que acontece, porém, quando estamos diante de um comportamento bizarro, quando vivemos um imprevisto, quando encontramos uma anomalia em relação à ordem social consolidada? $\mathrm{O}$ ator se vê diante de um fracasso do fundo de recursos de compreensão, fracasso que denomino breakdown, ou ruptura da compreensão. Trata-se de obstáculos em relação aos quais não podemos ficar indiferentes: mesmo os agentes "ordinários", como o observador especializado cuja profissão é explicar (o cientista social com suas perguntas cognitivas, mas também o investigador de polícia e o jornalista investigativo, solicitados a explicar o ocorrido), formulam perguntas contrafatuais que permitem descrever o comportamento do outro sob diversos pontos de vista, na tentativa de recuperar a inteligibilidade interrompida. A ocorrência de um breakdown cria, assim, um sentimento de inadequação, suscitando ao mesmo tempo uma necessidade ou solicitação de explicação. Temos a necessidade de ampliar a perspectiva, de comunicar com outros atores que conhecem (ou observaram) o evento anômalo para poder inseri-lo em uma constelação inteligível. Dirigimo-nos a quem, conforme pensamos, possa nos ajudar a ampliar o olhar, a descrever o comportamento alheio com outros pontos de vista, na tentativa de recuperar a familiaridade interrompida. A explicação tem assim a ver com as modalidades que tornam possível a operação de recomposição da situação de bloqueio. 
Em suma, estou investigando as circunstâncias em que emerge a solicitação de explicação. Afirmei que a exigência de explicação surge quando a teoria usada até aquele momento não dá conta do evento em questão. Não podemos mais dar por certo o agir do outro. O correio está aberto todas as manhãs, mas hoje, estranhamente, está fechado. Devo solicitar explicações para esclarecer o obstáculo ${ }^{6}$. Outras vezes, aquilo que era óbvio e (implicitamente) compreendido como evidência não ambígua torna-se, repentinamente, objeto de perplexidade e gera solicitaçôes de explicação: vejo pessoas vestidas de branco, mas têm o semblante pesaroso e constrito. Não consigo inserir o evento no mapa da realidade que construímos; faltam-me os nomes e as categorias para dar um sentido ao que vejo. Solicito esclarecimentos, e explicam-me que na China, durante os funerais, é tradição vestir-se de branco (não conhecia as regras que permitem estabelecer qual o significado daqueles trajes brancos).

Em que consistem o breakdown e o estado de bloqueio aí implicado? A ruptura pode coincidir com a simples ignorância de determinados fatos: desconhecemos a resposta de uma pergunta (por exemplo, quem é o autor de Traumdeutung) e pedimos uma explicação. $\mathrm{Na}$ escola italiana ainda se usa a expressão "explicar um autor", para se referir ao trabalho do professor que reduz essa distância cultural cognitiva. Em outros casos, a situação de bloqueio é induzida por uma forma de incompreensão: acreditava saber onde me encontro, mas, em vez disso, não consigo dar sentido ao que as pessoas à minha volta fazem. Suponha, por exemplo, que você está próximo de um grupo de pessoas que anda pela rua. Trata-se de uma demonstração política? De uma manifestação religiosa? De uma festa popular? A situação não é muito diferente daquela do médico que está diante de sintomas desconhecidos e deve cogitar um diagnóstico, consultando livros e colegas.

Em geral, podemos dizer que as perplexidades que uma explicação pretende resolver dizem respeito a três tipos de perguntas: "como é possível?”, "por quê?" e "o que significa?".

No primeiro caso, a explicação permite esclarecer, por exemplo, como é possível que Phelps tenha vencido mais uma vez (dadas as expectativas contrárias ou apesar da idade). No segundo, estamos diante de uma "pergunta-porque", isto é, trata-se de explicar por que alguma coisa ocorreu. Por exemplo, por que as taxas de suicídio são mais elevadas em condiçôes de vida fortemente urbanizada? Resposta: porque o percentual de suicídios é função da assimetria entre os modelos de definição das aspirações individuais e as possibilidades efetivas de realizar as aspirações - é função da anomia, para
6. Nem sempre é um obstáculo que desencadeia a necessidade de explicação. A simples curiosidade disciplinar pode levar o cientista social a formular perguntas cognitivas, como esta: por que o boxe, esporte das classes aristocráticas, se transformou no curso do século xx em esporte da classe operária, dando lugar a outras formas de esporte (o tênis ou o golfe) como símbolos de status? 
7. Respondendo a uma pergunta sobre Hegel feita pelo aluno Drury (1981, p. 121), Wittgenstein observou: "Hegel parece-me estar sempre querendo dizer que coisas que parecem diferentes são na realidade iguais. $\mathrm{O}$ meu interesse, porém, é mostrar que coisas que parecem iguais são realmente diferentes. Pensei em usar como mote de meu livro uma citaçẫo a Rei Lear 'Vou ensinar-lhe diferenças". O mesmo Wittgenstein (1993) adverte contra o preconceito da explicação, isto é, a tendência a considerar que seja sempre necessário identificar causas em vez de iluminar certos fenômenos com uma visão clara ou de aceitar que algumas práticas não podem ser explicadas de modo incontroverso. Quando as crianças perguntam por que existe a morte, por que é preciso ir à escola ou por que comemos animais, percebemos que não há uma instância transcendental à qual recorrer para além do "é assim que fazemos". A famosa alusão de Wittgenstein à camada de rocha (cf. Wittgenstein, 1953, $\$ 217$ : “Se esgotei as justificativas, então atingi a rocha dura e minha pá fica retorcida. Estou então inclinado a dizer: 'é simplesmente assim que eu ajo"') é sintomática de certa impotência diante do esforço de explicar os fundamentos de nossa forma de vida. empregar a célebre expressão de Durkheim - a que os atores estão sujeitos, e a anomia é mais elevada nos agregados urbanos do que nas pequenas comunidades rurais. No último caso, trata-se de fornecer uma resposta a perguntas como a seguinte: o que significa aquele detalhe no quadro (ou aquele sintoma anômalo)?

\section{O episódio explicativo}

A observação que gostaria de formular neste ponto é a seguinte: podemos explicar por razões diversas (para esclarecer um evento, para convencer alguém, para parecer racional) e de diferentes modos. Porém, não obstante a pluralidade de situações e modalidades explicativas, podemos identificar uma primeira característica distintiva da explicação quando ela é apresentada como resposta a uma situação de breakdown. Tenho agora condições de analisar a sequência que vai do breakdown à (eventual) explicação esclarecedora sequência que chamo de "episódio explicativo" (cf. Bromberger, 1968, pp. 72-105). O episódio explicativo inclui um breakdown, uma necessidade de explicação ou, simplesmente, uma situação de bloqueio e de pergunta - um explicador capaz de fornecer uma resposta e um outro ator, o ouvinte ou audiência, em estado de perplexidade. Se a explicação fornecida é aceita e aplicada (isto é, se é satisfeita a necessidade de compreensão, com a explicação daquilo que antes bloqueava), o estado de compreensão é restaurado e a explicação funciona como recurso para retomar a série interrompida. Consideremos o seguinte exemplo. Meu filho me pergunta por que as pessoas tiram os sapatos antes de entrar em certo edifício. Explico-lhe que se trata de uma mesquita e comento algumas das normas vigentes entre as pessoas de fé islâmica. Agora meu filho sabe que se estiver em uma mesquita, os fiéis tirarão os sapatos; sabe que se $\mathrm{X}$, então (provavelmente) Y. Trata-se de um avanço cognitivo, uma vez que meu filho se tornou capaz de traçar um número maior de distinçôes. É este, também, o critério de êxito da explicação: os resultados não são só comunicados, mas usados para remapear a paisagem social ${ }^{7}$. Um episódio explicativo propriamente dito implica, portanto, uma mudança na audiência, que, no início, estava perplexa mas que ao longo do episódio adquiriu as categorias que lhe permitiram reenquadrar alguns fatos; no final, ela foi capaz de utilizar o conhecimento adquirido em outras circunstâncias (cf. Achinstein, 1977, pp. 1-15).

Recoloquemos então a pergunta: que tipo de ato é o de explicar? O que é uma explicação? Uma explicação pode ser considerada um ato em rela- 
ção ao qual faz sentido perguntar: quem o forneceu? Quando? Com quais termos? Em benefício de quem? Mas é também algo a respeito do qual faz sentido perguntar: está formulado claramente? É convincente? Não temos aí dois tipos de explicação, mas dois significados da palavra "explicação": um refere -se a certo tipo de prestação comunicativa (executada por alguém que assume o papel de explicador no curso de um episódio explicativo) e o outro a algo mais abstrato, digamos, o produto ou o conteúdo cognitivo de tal prestação. Da explicação-produto, dizemos que é certa ou errada, completa ou incompleta, clara ou não. Uma explicação sempre implicará um ato ou prestação comunicativa (o médico que explica a dor de estômago, ato que tem uma certa duração), ou implicará o produto de tal ato (a explicação do médico, que não é caracterizável por uma duração).

Consideremos o primeiro significado. A rigor, explicar não é um ato apenas linguístico, mas comunicativo. Precisamente, explicar é um ato ilocutório, como prometer ou avisar, executado por meio da asserção de determinadas locuções em determinados contextos. Na qualidade de ato ilocutório, embora exprimindo as mesmas locuçôes (o mesmo conteúdo proposicional), explicar se distingue de outros atos em virtude da força ilocutória com a qual é expresso; em outras palavras, distingue-se pelo tipo de ato ilocutório executado, que é um ato expositivo. Os atos ilocutórios expositivos assumem a função metadiscursiva de organizar e elucidar o que se está dizendo. Podemos pensar, nesse sentido, em outros atos ilocutórios com os quais o ato de explicar está estreitamente relacionado, como, por exemplo, o ato de elucidar, de referir-se ou de informar. Todos eles exigem uma audiência que os reconheça e, assim, os aceite (na qualidade de desculpas válidas ou não, como justificativas suficientes ou não).

Pode-se presumir que a explicação seja também um ato comunicativo pela definição mesma de explicador. Como afirma Alessandro Pizzorno (1989, p. 169), o explicador não é aquele que faz parte da ação (ou melhor, ele faz parte da ação de explicar, mas não da ação que é "objeto" da explicação), mas quem reconstrói a ação "em retrospecto" (ou post hoc, a partir de lembranças, documentos, relatos, testemunhos). Fixando-se e destacando-se, por assim dizer, do contexto de sua produção, a ação que ele propõe explicar é registrada em vista de um fim ulterior: a elaboração e a comunicação a outros. O explicador, portanto, é aquele que permanece separado da ação, observando-a e descrevendo-a para comunicá-la (contá-la, especificá-la) a terceiros. Imaginemos uma criança que folheia um álbum de fotos de família e, curiosa por uma foto em particular, pergunta à mãe: "o que você está 
fazendo aqui, mamãe?”. Nesse ponto, a mãe se coloca em terceira pessoa em relação à ação representada na fotografia e fala ao filho seguindo um novo "jogo linguístico", o jogo do explicar. A explicação, portanto (e é esta a sua segunda característica distintiva), é sempre explicação $a$ alguém (além de explicação de alguma coisa).

Consideremos ainda outro exemplo: como pai, compartilho certas regras familiares com meu filho para poder interagir com ele. Além de ser pai, sou também psicanalista, e encontrando-me com dois colegas de trabalho, descrevo-lhes algumas ações de meu filho. Nesse caso, terei de traduzir as açôes de meu filho na linguagem de meus colegas, usando outros termos e outras categorias que não aquelas que emprego na qualidade de pai. Se eu fosse um jungiano, por exemplo, em vez de falar do entusiasmo de meu filho no parque sobre a colina atrás de casa, poderia me referir à simbologia da montanha sagrada. $\mathrm{O}$ importante aí é que não me limito a identificar o ato ou o estado, mas lhes dou um nome (digo, por exemplo, que determinado estado exprime certo "arquétipo"). Procedo, assim, como Freud em relação ao pequeno Hans. Hans falava de cavalo e Freud o redescrevia na metalinguagem da psicanálise com o termo "pai". As ações são explicadas conforme as categorias sistemáticas de uma metalinguagem. A pessoa que explica deve, assim, assumir um compromisso em relação à própria descrição da ação, justicando-a e apresentando-a na forma de um saber organizado e transmissível, usando os termos de uma linguagem já conhecida e disciplinada, que servirá para comunicá-la inclusive aos que não pertencem ao contexto em que a ação ocorreu.

Se podemos afirmar que a explicação é (tipicamente) gerada em situações de breakdown e que, no plano pragmático, é uma atividade de natureza (tipicamente) comunicativa, consistente na descrição que um ator social (o explicador) oferece a um outro ator social (a audiência), no plano cognitivo do conteúdo (a terceira característica distintiva), a explicação coincide não só com o produto do ato comunicativo, mas com o poder de redescrever tal produto, de redescrever a ação que é objeto de explicação.

\section{As redescrições}

No sentido mais geral, as redescrições configuram-se como modalidade para realocar as açôes em categorias mais apropriadas do ponto de vista explicativo, isto é, elas se configuram como a substituição de descrições por descrições que satisfazem, de modo mais apropriado, o déficit de com- 
preensão que emerge em situação de breakdown. Entre os elementos que são passíveis de redescrição, podemos pensar na identidade do ator. Variando a identidade atribuída anteriormente aos atores, recolocamos a ação em um novo contexto e relemos a ação imaginando-a orientada por_um outro sujeito de ação. Consideremos, por exemplo, a pergunta: por que os senhores da Idade Média faziam enormes doações à Igreja? Seriam loucos? A seguinte resposta torna aquela ação explicável: esses senhores não eram loucos, dada a crença nas trocas entre o mundo terreno e o ultraterreno por meio de doações como forma de garantir acesso ao purgatório. Recoloco a ação em um novo contexto histórico e cultural e a releio imaginando-a orientada por outras crenças e finalidades. Em suma, reidentifico o ator. A mudança das condições de identidade descreve um novo ordenamento dos fins e das caracterizações com as quais os atores, do ponto de vista do observador, orientam suas ações. Dado que os qualificadores adverbiais incluídos na primeira atribuição não são idênticos aos incluídos na segunda atribuição, esta descreve uma outra identidade.

Consideremos outro exemplo: a prática de dar presentes no Natal. Como é sabido, gastamos tempo, dinheiro e esforço ao escolher e comprar os presentes adequados. Caso se pergunte, porém, os motivos desse investimento, notaremos muita ambivalência: o Natal se tornou muito comercial, os presentes não têm mais um significado natalino, ao contrário, traem a matriz cristã da festa e muitos são objetos de consumo inúteis. Por que então o rito sobrevive apesar desse desencanto? A explicação é que presenteamos para evitar que o outro (o outro significativo) pense que não o consideramos. Não presentear é, de fato, um sinal do escasso valor atribuído à pessoa. A prática do rito não é animada por um consenso normativo em torno do significado do Natal - e pela fé em tal festa -, mas por um vínculo induzido pelo saber a respeito do significado que a nossa ação terá aos olhos do outro (somos vinculados pelo conhecimento do significado que o nosso gesto - presentear ou abster-se de fazê-lo - assumirá na interpretação do destinatário de nosso gesto). Ora, o que fizemos ao oferecer essa explicação? Recolocamos as ações em um contexto que as torna plausíveis, estabelecendo uma rede de relaçôes entre linguagem e cultura reconstruíveis em torno de uma situação, de modo a redefinir-lhes o significado. 


\section{A função identificante e o efeito perlocutório}

Sublinhei como o episódio explicativo contém três aspectos: o breakdown, o fornecimento da explicação e a sua recepção por parte de uma audiência. $\mathrm{O}$ que queremos dizer com audiência? Em sentido estrito, ela pode ser considerada um conjunto de especialistas que interagem entre si no âmbito de um paradigma ou de uma determinada disciplina. Em sentido amplo, porém, coincide com o contexto no qual ocorre o fornecimento da explicação. Ora, as explicações (dos cientistas sociais) são não só destinadas a uma audiência, mas têm sobre esta um efeito perlocutório em virtude da possibilidade - que elas oferecem - de reutilizar o próprio conteúdo como premissa para escolhas, ações e identificações posteriores. É precisamente a disponibilidade de modos ulteriores de reconhecer e responder a desafios simbólicos e a situações de breakdown que torna as explicações não só prestações comunicativas e produtos cognitivos, mas vocabulários de identificação.

Suponhamos que estejamos às voltas com o relato de um evento histórico, de um embate político. Suponhamos, ainda, que documentos confiáveis evidenciem correlações entre o fenômeno histórico e a situação econômica de determinado país e que evidenciem também, de modo justificado, o papel da pobreza como antecedente causal do embate político. Cabe então perguntar: está toda aí a explicação? Não transmite nada mais à audiência? As explicações nos permitem "ver" de modo diverso as nossas açōes e as dos outros. Quando Freud explica que os atores estão expressando desejos inconscientes sob a forma de pulsões libidinais (são mediadas pelos vínculos impostos pelo contexto familiar); quando Durkheim explica que os atores reforçam elos de solidariedade e mantêm a integração social; quando Marx, por fim, nos $M a$ nuscritos econômico-filosóficos de 1844 explica o que quer dizer ser trabalhador e ser trabalhador alienado, explicando, ao mesmo tempo, como as interaçôes são expressões de relaçôes sociais determinadas pela localização dos atores nas relações de produção, o que esses autores estão fazendo é elaborar uma redescrição do que quer dizer ser membro da nossa sociedade.

Mas as explicaçôes não se limitam a fornecer um vocabulário para identificar as açōes de nossa comunidade. Elas nos auxiliam a identificar atores e ações longínquas no tempo e no espaço, familiarizando-nos com atores e ações que temos dificuldade de compreender. É precisamente esta, diria Rorty (1980, pp. 359-360), a importância dos antropólogos e de obras como Os argonautas do Pacífico Ocidentalem relação a outras sociedades; dos sociólogos 
e de obras como Asylums (e também, por que não, Germinal) em relação a comunidades fechadas como a dos mineradores de Anzin ou a de sujeitos internados em hospitais psiquiátricos; de historiadores e de obras como Montaillou: povoado occitânico de 1924 a 1934 em relação a outros períodos históricos. Essas obras fornecem vocabulário mais amplo e perspícuo para ver e dizer coisas ulteriores sobre nós mesmos.

Tentei mostrar como a explicação está ligada, de modo perlocutório, à compreensão. Ela constrói um vocabulário que oferece, retrospectivamente, possibilidades de compreensão e de respostas ulteriores a breakdowns. Trata-se de uma compreensão desenvolvida (mais do que retomada), como a do sujeito que afirma, após haver lido algumas obras de Balzac, compreender então quais eram as relaçôes intrafamiliares na burguesia francesa do início do século XIX. Não que fosse necessário explicar o que significa "burguesia francesa”. Não se trata de um problema ilocutório, mas perlocutório: a descrição incorporada na narração de Balzac é iluminadora e persuasiva e, assim, a audiência (o leitor) compreende (mais precisamente, reidentifica) diversamente o termo "burguesia francesa”. Podemos nos referir a essa função da explicação como a consequência que ela tem sobre a pré-compreensão da audiência.

\section{A função normativa}

Ao introduzirem a noção de accountability, os etnometodólogos evidenciaram, pela primeira vez, a função normativa da explicação. Toda situação social é de fato organizada, e é organizada precisamente para tornar as suas propriedades investigáveis, registráveis e capazes de serem relatadas, em suma, accountable: "As atividades por meio das quais os membros da sociedade produzem e geram situações organizadas de relações cotidianas são idênticas aos procedimentos usados pelos membros para torná-las 'explicáveis' [accountable]" (Garfinkel, 1967, p. 1) ${ }^{8}$. As explicações, segundo um princípio de simetria, são ao mesmo tempo explicações sobre determinados contextos sociais e características (ou partes) de tais contextos.

Prova dessa normatividade é dada pela circunstância de que se as ações de um ator não concordam com as respostas da comunidade (respostas que, em determinado momento, a comunidade veio a considerar corretas e que assumiram assim, ainda que de forma provisória e implícita, o estatuto de um padrão intersubjetivo) e se tais ações não podem ser reconstruídas como simples erros, brincadeiras ou outras pequenas anomalias que a elasticidade das regras permite tolerar na prática ${ }^{9}$, a comunidade não poderá regular tal
8. A esse respeito vale a pena assinalar o nexo entre accountability e controle social: se quisermos maximizar os benefícios que a sociedade em que vivemos oferece - benefícios relativos à saúde, legais, profissionais, crediários, fiscais - seremos instados a prestar contas de nós mesmos e de nossa vida, registrando nosso passado, arquivando dados relevantes, gerindo nossa identidade pública e tornando-nos, assim, nós mesmos uma organização eficaz.

9. Um ponto-chave a propósito das consideraçôes de Wittgenstein sobre seguir uma regra diz respeito à plasticidade pública das regras, a circunstância de que $o$ significado da regra $x$ não é fixado completamente (como gostaria uma concepção da determinação completa da normatividade), mas continuamente plasmado pelo uso. Dizer que um ato é compreendido sobre o pano de fundo de regras (sendo descrito como a aplicação de uma regra) é bem diferente de dizer que é determinado por uma regra. 
comportamento. O que acontece em tais casos? Voltamo-nos à comunidade científica esperando ampliar o repertório de categorias que podem servir para regular o ato. Em tais casos, mediante a produção de novas categorias e a articulação de uma explicação, a comunidade opera reflexivamente sobre seus próprios limites, redescrevendo e reclassificando as açôes (incompreendidas) (cf. Hacking, 1986). Temos, assim, o seguinte processo: os breakdowns ameaçam a persistência daquelas formas de reconhecimento que permitem às diversas unidades coletivas avaliar atos e preferências e, então, manter uma identidade no tempo. A instituição de sanções (excluir e punir) protege tal persistência garantindo os limites e, portanto, o pertencimento a determinada unidade coletiva e seu caráter distintivo. A explicação, por sua vez, funciona como instituição reparadora, inserindo-nos em um metaplano em relação ao das práticas interrompidas, de modo a reenquadrar o fenômeno inexplicado.

O próprio termo "explicabilidade" (accountability) exprime a conjugação do aspecto semântico com o normativo. Ser responsável (accountable) pelas próprias atividades significa tanto ser capaz de apresentar as razóes que explicam o sentido de tais atividades, como ser capaz de fornecer justificativas que insiram tais atividades em um quadro normativo. Podemos, portanto, afirmar que as regras de interação social são reconstruídas e sustentadas, sobretudo, pela reiteração de ações que se conformam às regras, mas são igualmente sustentadas pelo fornecimento de explicações que esclarecem os casos de violação, protegendo a ordem normativa dos processos entrópicos de breakdown.

\section{Conclusão}

Para concluir, podemos dizer que enquanto nas situações de práticas consolidadas os breakdowns são antecipados, nas situações em que se percebe uma concorrência anômala de modos de descrição das ações, explicar assume um papel relevante, configurando-se como tentativa de restaurar a ação interrompida. A explicação, junto com outras "peças" do equipamento cultural, como as histórias, as desculpas e as justificativas, oferecem um instrumental (tool-kit) de recursos que os atores podem utilizar para enfrentar a batalha contra as anomalias da inteligibilidade. Tendo como sua condição de satisfação a solução das situações de obstáculo, as explicações coincidem com um procedimento para restaurar a compreensão interrompida. Se essa interpretação do papel de explicar está correta, trata-se de uma prática 
estreitamente correlata à pergunta sociológica por excelência, a pergunta relativa às técnicas que asseguram a coesão da sociedade.

Sem atribuir uma função salvadora à explicação, vale ressaltar como na origem da operação de explicar está a exigência de sair da incerteza (restabelecendo a inteligibilidade do agir). O anseio de explicação é, em definitivo, um complemento indispensável da interação social e talvez também um sintoma a ser diagnosticado ${ }^{10}$.

\section{Referências bibliográficas}

Achinstein, P. (1977), "What is an explanation?”. American Philosophical Quaterly, 14: $1-15$

Brandom, R. (1988), "Varieties of understanding”. In: ResCHER, R. (org.). Reason and rationality in natural science. Lanham, MD, Lanham University Press.

Bromberger, S. ([1963] 1968), “An Approach to Explanation”. In: Butler, R. J. (ed.). Analytical Philosophy. Oxford, Basil Blackwell.

Draper, S. W. (1988), “What's going on in everyday explanation?”. In: AntaKi, C. (org.). Analysing everyday explanation. Londres, Sage.

DraY, W. (1957), Laws and explanations in history. Oxford, Oxford University Press.

Drury, M. O’C. (1981), “Conversations with Wittgenstein”. In: RheEs, R. (ed.). Ludwig Wittgenstein: Personal Recollections. Oxford, Blackwell.

FISH, S. (1989), Doing what comes naturally: change, rhetoric and the practice of theory in literary and legal studies. Oxford, Clarendon Press.

Garfinkel, H. (1967), “What is Ethnometodology”. In: . Studies in ethnometodology. Engelwood Cliffs, NJ, Prentice Hall.

GeERTZ, C. (1973), Interpretations of culture. Nova York, Basic Books.

Hacking, I. (1986), “Making up people”. In: Heller, T. C.; Sesna, M. \& Wellbery, D. E. (orgs.). Reconstructing individualism. Stanford, Stanford University Press.

Hempel, G. \& Oppenheim, P. (1948), “Studies in the logic of explanation”. Philosophy of Science, 15 (2): 135-175.

Pizzorno, A. (1989), "Spiegazione come reidentificazione". Rassegna Italiana di Sociologia, xxx (2): 169.

Rorty, R. (1980), Philosophy and the mirror of nature. Nova Jersey, Princeton University Press.

Rотн, P. A. (1989), "How narratives explain”. Social Research, 56 (2): 467-469.

SPARTI, D. (1992), Se um leone potesse parlare: indagine sul comprendere e lo spiegare.

Florença, Sansoni.
10. Nessa vontade de mitigar o indeterminado, a nossa necessidade de explicação está plena de ansiedade e revela seu vínculo com uma pulsão de controle. Retornamos, assim, ao mencionado diagnóstico de Wittgenstein a respeito do preconceito da explicação (cf. nota 9). 
. ([1995] 2002), Epistemologia delle scienze social. Bolonha, Il Mulino.

SPENCE, D. (1982), Narrative truth and historical truth: meaning and interpretation in psychoanalysis. Nova York/Londres, W. W. Norton \& Company.

wittgenstein, L. (1953), Philosophical investigations. Oxford, Blackwell.

(1993), "Remarks on Frazer's 'Golden Bough'”. In: KlagGe, J. C. \&

Nordmann, A. (orgs.). Philosophical occasions - Ludwig Wittgenstein: 1912-1951.

Indianapolis, Hackett Publishing Company.

Wright-Mills, C. (1940), "Situated action and the vocabularies of motive". American Sociological Review, 5: 904-913.

\section{Resumo}

O que está acontecendo aqui? Da explicação das ações à atividade de explicar

$\mathrm{O}$ artigo é um trabalho de natureza metateórica que investiga uma gama de problemas ligados ao que fazemos quando explicamos as ações. A explicação é apresentada no quadro pragmático do explicar como prática teórico-comunicativa. O objetivo é analisar como certos atores sociais operam quando a praticam e esclarecer que tipo de atividade é a atividade por meio da qual explicamos as açōes dos outros. A identificação e a descrição das açôes são inseridas na atividade mais ampla de atribuir motivos e intençōes, cuja finalidade é tornar as ações inteligíveis. A consequência dessa perspectiva é deslocar a questão da explicação do plano essencialmente epistemológico para o plano sociológico, ligado aos contextos e às circunstâncias em que se usa a explicação como recurso para agir e interagir.

Palavras-chave: Filosofia das ciências sociais; Explicação; Ação.

Texto enviado em 30/1/2014 e aprovado em 27/2/2014.

Davide Sparti é professor do Departamento de Ciências Sociais, Políticas e Cognitivas da Universidade de Siena. É autor de Se un leone potesse parlare: indagine sul comprendere e lo spiegare (1992), Soggetti al tempo: identità personale fra analisi filosofica e costruzione sociale (1996), Epistemologia delle scienze sociali (2002), Limportanza di essere umani: etica del riconoscimento (2003), Suoni inauditi: l'improvvisazione nel jazz e nella vita quotidiana (2005). E-mail: davide.sparti@ unisi.it.

\section{Abstract}

What is happening here? From explanation of the actions to the act of explaining

This meta-theoretical article approaches a range of problems concerning to what we do when explaining actions. Explanation is presented in a pragmatic framework: explaining is a theoretical communicative practice. The goal is to analyze how social actors go on when they explain and to elucidate what kind of activity is to explain other people's actions. To identify and to describe actions is part of a broader activity of ascribing motives and intentions, activity that aims to assure action intelligibility. This perspective implies to shift the explanation problem from the epistemological level to the sociological level, tied to contexts and circumstances where explanation is a resource to act and interact.

Keywords: Philosophy of social sciences; Action; Explanation. 